\title{
Development of a modern comprehensive technology for extending the life of turbine blades of SGT Siemens power plants and alike
}

\author{
Olga Berdnik $^{1,{ }^{*}}$, Irina Tsareva $^{1},{\text { Ludmila } \mathrm{Krivina}^{1} \text {, and Yuriy Tarasenko }}^{1}$ \\ ${ }^{1}$ Institute of Applied Physics of the Russian Academy of Sciences, Nizhny Novgorod, Russia
}

\begin{abstract}
The post-operational state of the material of the guide blades as a part of the SGT-800 Siemens unit has been analysed in this study. The detailed analysis of the high-loaded zones has been carried out. The technology of the prolongation of blades resource has been developed on the basis of the carried-out study.
\end{abstract}

\section{Introduction}

The question of elaboration of the technology of prolongation of blades resource of imported power stations becomes more and more relevant.

Nozzle blades of turbines, especially of the first step, work in very difficult operating environment. They are intended to provide a required rotation angle of the gas stream leaving a combustion chamber. They meet the gas stream having extremely nonuniform distribution of temperatures from a core to the periphery with the difference of several hundred degrees. [1]. To define the possibility of the resource prolongation, the state of the material of the 1st step guide blade of SGT-800 Siemens having completed an operating time from the beginning of operation 24918 equivalent hours was gauged.

\section{Methods and discussion on the results}

At visual inspection of the blade, cracks (with a length of $\sim 30 \mathrm{~mm}$ ) near the cooling channels on the exit edge of a blade airfoil from the forepart were found (fig. 1a) [2].

The heat-resistant covering ( $250-300$ microns thick) kept the integrity only on platform of blade locking piece (fig. 1b), it is practically absent on a blade airfoil because of the erosive wear. The ceramic coating of zirconium dioxide has hardness in the range of $\mathrm{HV}=890-950 \mathrm{~kg} / \mathrm{mm}^{2}$ and the parameter of the surface roughness of $\mathrm{R}_{\mathrm{a}}=5,475$ microns.

\footnotetext{
*Corresponding author: npktribonika@yandex.ru
} 


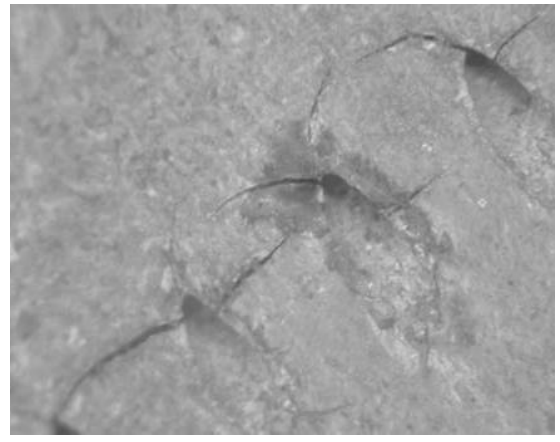

a

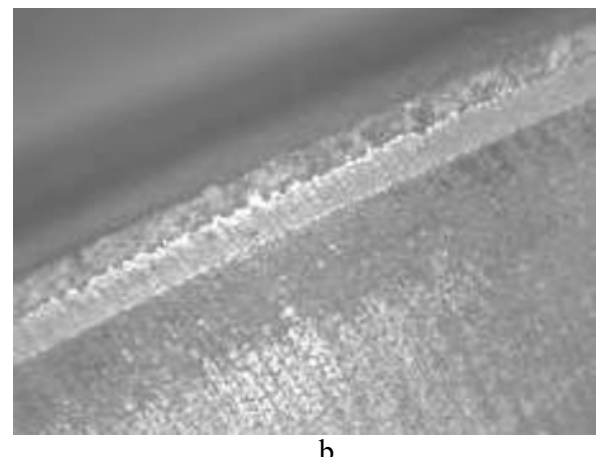

$\mathrm{b}$

Fig. 1. Appearance after the operation of the guide blade of the 1st step: a - defects (cracks on the trailing edge); $\mathrm{b}$ - the remained covering on the blade locking piece, (x32).

The chemical analysis of blades basic material was carried out by a non-destructive method on Niton XL2 Analyzer and by the destructive method on samples by the atomicadsorption method. Blades are made of the heat-resistant nickel alloy having the following element structure: $\mathrm{Cr}-12,7 \%$; Co-8,85\%; Ta-4,45\%; Ti-4,23\%; W-3,65\%; Al-3,2\%; Mo$1,56 \%$; Hf- $1,0 \%$; Fe- $0,62 \%$; V-0,3\%; Nb-0,3\%; $\mathrm{Ni}$ - basis metal. For carrying out researches a blade was cut on blanks. The X-ray crystal analysis established that the phase composition of the materials of a blade airfoil and a blade locking piece is identical and represents the combination of a $\gamma$-solid solution of nickel (with unit spacing of the crystalline lattice $\mathrm{a}=3,56 \mathrm{~A}^{\circ}$ for a blade airfoil and $\mathrm{a}=3,58 \mathrm{~A}^{\circ}$ for a blade locking piece) and an intermetallic phase $\gamma-\mathrm{Ni}_{3} \mathrm{Me}$ where "Me" generally designates alloying elements of the metals as a part of alloy forming $\gamma$-solid substitutional solution. On diffraction patterns the broadening of reflexes (111) and (200) $\mathrm{Ni}$ is observed; it is caused by a coherence of nickel lattices and the intermetallic phase. In material of a blade airfoil, the main orientation of grains of a nickel matrix is the crystallographic direction (200) which is shown as a result of a directional crystallization in the production of blades. Mechanical tensile tests of samples (cut out from blade locking piece and from a blade airfoil) were carried out at indoor temperature and at a temperature of $850{ }^{\circ} \mathrm{C}$ by Tinius Olsen H100KU. Only cutting of flat micro-samples $(1,5 \mathrm{~mm}$ thick) for carrying out physical tests was possible to make from this blade because of the composite curved profile of the blade, small thickness of walls (from 1,2 to $3 \mathrm{~mm}$ ) and existence of a large number of the cooling openings (388 pieces). The first table shows that results of the tests of the samples, cut out from a blade locking piece, at indoor temperature and $850{ }^{\circ} \mathrm{C}$ correspond to data for this alloy.

The sample which was cut out from a blade airfoil near the cooling openings from the forepart and the sample which was cut out from a zone near the cooling openings from the back side have decreased values of strength and plastic characteristics.

Method of relaxational tests was used for the definition of a yield point $\left(\sigma_{\mathrm{T}}\right)$ and a micro-plastic limit $\left(\sigma_{0}\right)$ of a zone material that is as close as possible to the cooling channels.

Similar tests on the samples that were cut out from a blade locking piece were carried out for comparison. The received results are presented in the table 2 .

The analysis of the obtained data showed that near the cooling channels there is a decrease in mechanical characteristics of material observed: a micro-plastic limit - by 1,7 time, a yield point - by 1,3 times in comparison with the material of a blade locking piece. The greatest degradation of alloy is expressed in this zone. 
Table 1. The mechanical characteristics of material different zones of blades.

\begin{tabular}{|c|c|c|c|c|c|}
\hline \multirow{2}{*}{\multicolumn{2}{|c|}{ Place of cutting }} & $\begin{array}{c}\text { T of tests, } \\
{ }^{\circ} \mathrm{C}\end{array}$ & $\begin{array}{c}\text { Yield point } \\
\sigma_{0,2}, \\
\text { MPa }\end{array}$ & $\begin{array}{l}\text { Ultimate } \\
\text { strength } \\
\sigma_{\mathrm{B}}, \mathrm{MPa}\end{array}$ & $\begin{array}{c}\text { Unit elongation } \\
\qquad, \%\end{array}$ \\
\hline & & 20 & $\geq 800$ & $\geq 900$ & $\geq 4,0$ \\
\hline \multirow{3}{*}{$\begin{array}{l}\text { Blade } \\
\text { airfoil }\end{array}$} & $\begin{array}{l}\text { trailing edge of a } \\
\text { blade, the forepart }\end{array}$ & \multirow{7}{*}{20} & 555 & 790 & 4,2 \\
\hline & $\begin{array}{l}\text { trailing edge of a } \\
\text { blade, the back side }\end{array}$ & & 750 & 813 & 3,0 \\
\hline & $\begin{array}{l}\text { leading edge of a } \\
\text { blade }\end{array}$ & & 800 & 908 & 4,5 \\
\hline \multirow{4}{*}{\multicolumn{2}{|c|}{ Blade locking piece }} & & 860 & 930 & 5,5 \\
\hline & & & 840 & 922 & 7,0 \\
\hline & & & 850 & 930 & 4,6 \\
\hline & & & 870 & 959 & 6,0 \\
\hline \multirow{2}{*}{\multicolumn{2}{|c|}{ Blade airfoil }} & \multirow[t]{3}{*}{850} & 570 & 770 & 23 \\
\hline & & & 520 & 750 & 19 \\
\hline \multicolumn{2}{|c|}{ Blade locking piece } & & 680 & 845 & 26 \\
\hline
\end{tabular}

Table 2. The mechanical characteristics of material received by the method of relaxational tests.

\begin{tabular}{|c|c|c|c|c|c|}
\hline $\begin{array}{l}\text { Place of } \\
\text { cutting }\end{array}$ & № & \multicolumn{2}{|c|}{ Micro-plastic limit $\sigma_{0}, \mathrm{MPa}$} & \multicolumn{2}{|c|}{ Yield Point $\sigma_{\mathrm{T}}, \mathrm{MPa}$} \\
\hline \multirow{3}{*}{$\begin{array}{c}\text { Blade } \\
\text { locking } \\
\text { piece }\end{array}$} & 1 & 570 & \multirow{3}{*}{565} & 890 & \multirow{3}{*}{871} \\
\hline & 2 & 575 & & 855 & \\
\hline & 3 & 550 & & 870 & \\
\hline \multirow{3}{*}{$\begin{array}{l}\text { Blade } \\
\text { airfoil }\end{array}$} & 4 & 300 & \multirow{3}{*}{326} & 660 & \multirow{3}{*}{663} \\
\hline & 5 & 320 & & 680 & \\
\hline & 6 & 360 & & 650 & \\
\hline
\end{tabular}

Optical microscopes "Neophot 32", "Mikrokon" and a scanning microscope "TESCAN VEGA II" were used for the analysis of the macrostructure of the material. Macrostructural researches were conducted after grinding and etching by the Marble's etchant. On a surface of a blade airfoil part the diffusion layer by thickness of $\sim 250$ microns is found. The surface layer consists of an underlayer ( $~ 30-35$ microns thickness) and a diffusion layer ( 175 - 200 microns thickness). The interface between an original material and a diffusion layer is legible, free of defects and stratifications. The adhesion strength on the interface between an original material and a diffusion layer was estimated by the method of microindentation on a microhardness tester PMT-3 at loading $2 \mathrm{~N}$ on the indentor. Cracks, cleavages, layer separations and distortion of a print shape were not revealed in the indentation zone. Results of micro-hardness measurements from indentation depth, which were carried out on the surface of a blade airfoil (diffusion layer) and on the metallographic section (original material), are given in fig.2. It is shown that the microhardness of the original material (curve 1) does not depend on the indentation depth, its average value is $410 \mathrm{~kg} / \mathrm{mm}^{2}$. On the curve showing the microhardness for the working surface of a blade airfoil there is a section of decrease indicating existence of a layer of loss of strength up to 1,7 microns in depth. The microhardness of a diffusion layer (curve 2) is $\sim 1,5$ times greater than the microhardness of an original material. It is caused by oxidation and loosening of the surface layer.

Vickers hardness tests at load of $10 \mathrm{~N}$ (taken by an ultrasonic hardness tester MET-U1) showed values of hardness of the basic material of a blade airfoil and a blade locking piece: $\mathrm{HV}^{\text {airfoil }}=416 \mathrm{~kg} / \mathrm{mm}^{2}, \mathrm{HV}^{\text {locking piece }}=403 \mathrm{~kg} / \mathrm{mm}^{2}$. 


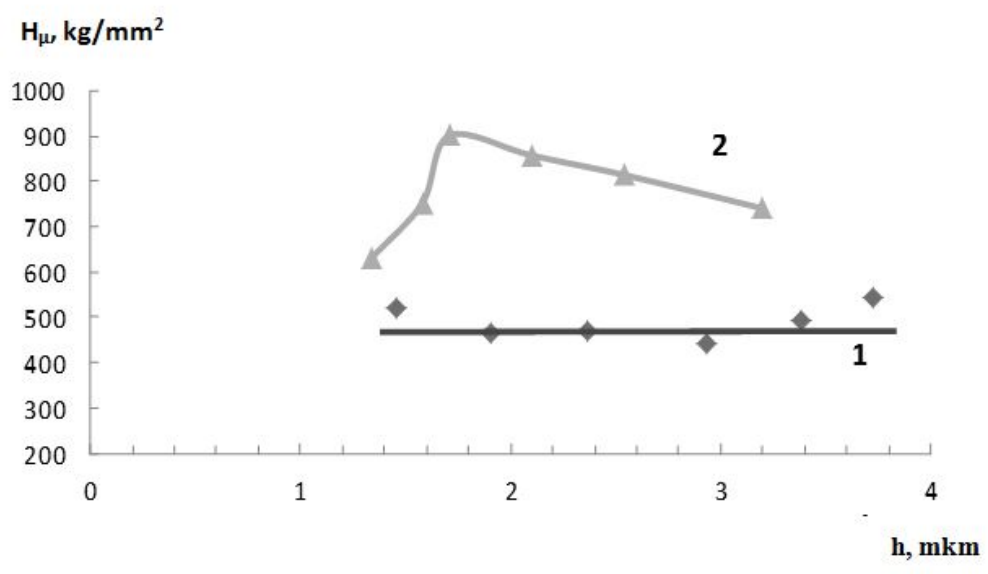

Fig. 2. Dependence of microhardness on the depth of indentation: 1 - basic material; 2 - diffusion layer

Detailed researches of a microstructure in its different zones were conducted to identify the reasons for the inhomogeneity of mechanical characteristics of the material of a blade. In general, material of blades has regular structure (fig. 3). For the analysis of the microstructure were chosen: a zone on the forepart of a blade airfoil; a zone near the cooling channels (material with the decreased value of mechanical indexes); a zone on the back side of a blade airfoil and a blade locking piece. The photo of the microstructure shows that the material on a blade body is not homogeneous, in the closest zones to the cooling channels precipitation of a carbide phase in the form of a grid are observed on the borders of grains. It leads to embrittlement of the material in these zones (fig. 3 e, f). The alloy microstructure is coarse-grained and grains have extended sinuous borders. Average grain size is in limits of $500-1000$ microns. Cracks on grains borders have not been revealed. In the material of the samples, which were cut out from zones near the cooling channels, the carbide phase was allocated on borders of grains in the form of large conglomerates, mainly on three grains boundary junction.

The stretched extended carbides were revealed also along borders of grains, thickness of a carbide grid changes from 0,5 to 2,0 microns (fig. 3e). In other zones of a blade carbide precipitations are isolated incidents and have the size of nearly 5 microns. The structure of material is strengthened by the intermetallic phase the size of which is from 0,45 to 2,0 microns. The separate flocculated prolate particles (up to 3,0 - 3,5 microns) are seen. In the structure, there are also precipitations of a secondary highly dispersed phase, uniformly distributed on grains bodies, with particle size $\sim 0,01$ microns. Volume concentration of an intermetallic phase makes nearly $40 \%$. The average size of the $\gamma^{\prime}$ - phase for material of a blade airfoil is in limits of 1,7 microns, for material of a blade locking piece of 1,5 microns that according to the literature data [3] corresponds to standard parameters of an intermetallic phase.

Using the Good Phase software, the analysis of morphological characteristics of the intermetallic phase structure was carried out. About 10 fields of visual fields (in the sum of 8000 particles) material of blade locking piece and blade airfoil were investigated. (table 3 ) [4]. 
Table 3. Average values of the intermetallic phase parameters of particles.

\begin{tabular}{|l|c|c|}
\hline Characteristics of the intermetallic phase & Blade locking piece & Blade airfoil \\
\hline Volume concentration of the intermetallic phase, $\%$ & 41 & 48 \\
\hline Concentration of the intermetallic phase, $\mathrm{cm}^{-2}$ & $43 \cdot 10^{6}$ & $36 \cdot 10^{6}$ \\
\hline Average maximal size, micron & 1,58 & 1,7 \\
\hline Average equivalent size, micron & 1,09 & 1,32 \\
\hline Average parameter of anisotropy of particle size & 0,69 & 0,67 \\
\hline Average factor of particle forms & 0,75 & 0,71 \\
\hline Average distance between particles, micron & 1,41 & 1,63 \\
\hline Average perimeter of particles, micron & 5,18 & 6,44 \\
\hline Average area of particles, micron & & 1,22 \\
\hline
\end{tabular}

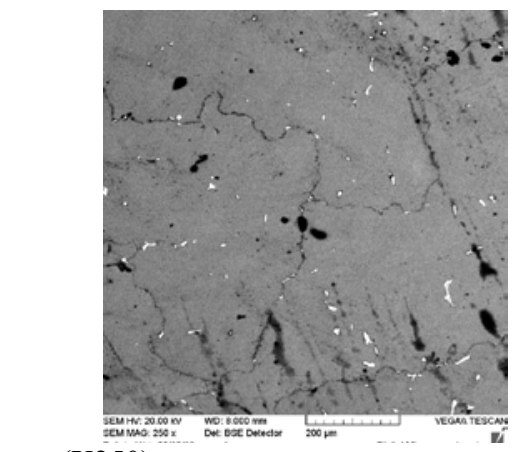

a, $(\mathrm{X} 250)$
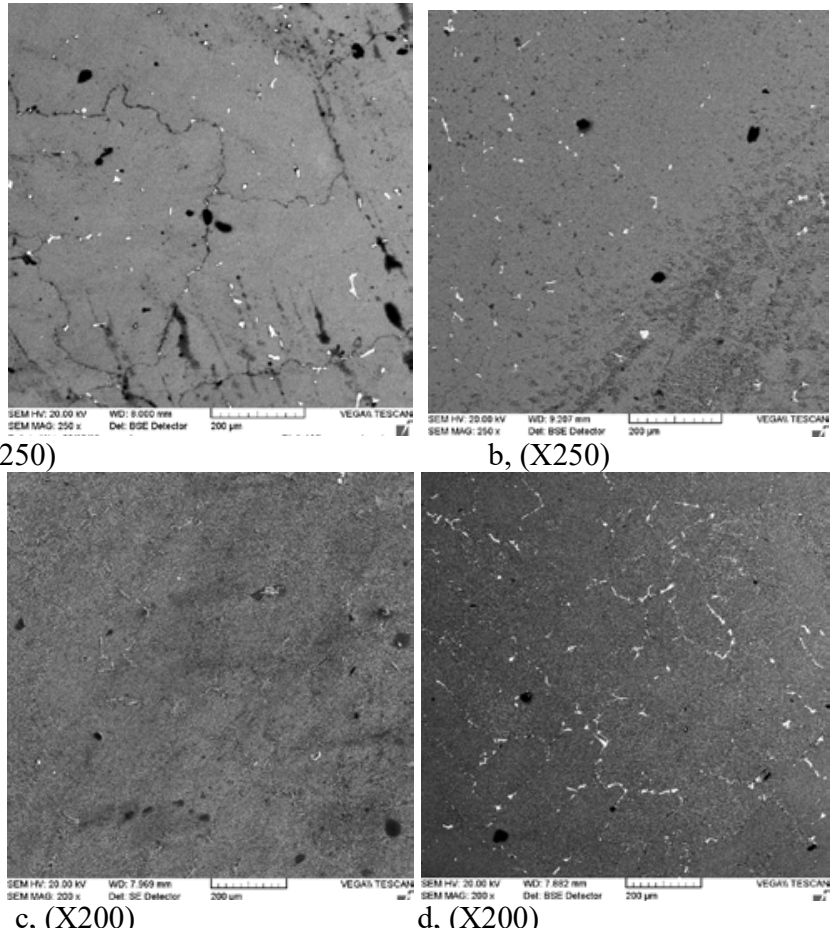

$\mathrm{b},(\mathrm{X} 250)$
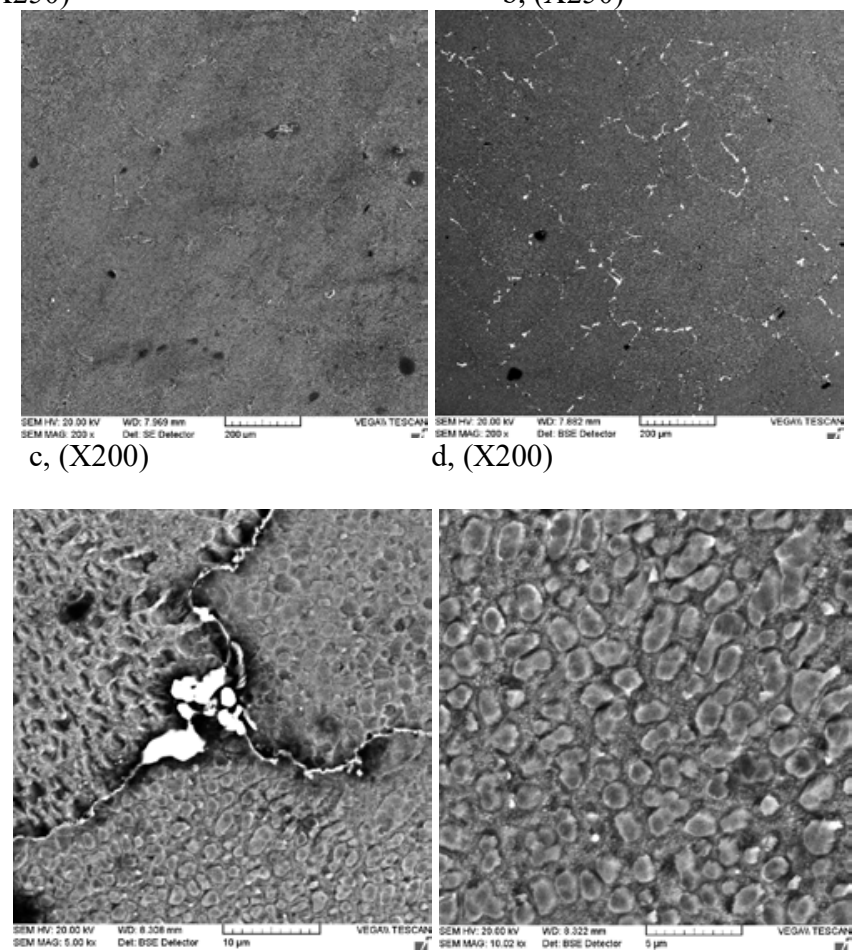

e, $(\mathrm{X} 5000) \mathrm{f}$,

(X10 000)

Fig. 3. Blade material microstructure: $\mathrm{a}-\mathrm{a}$ forepart of a blade airfoil; $\mathrm{b}-\mathrm{a}$ back side of a blade airfoil; $\mathrm{c}-\mathrm{a}$ blade locking piece; $\mathrm{d}, \mathrm{e}-\mathrm{a}$ blade airfoil near cooling channels; $\mathrm{f}-$ the middle of a forepart of blade airfoil 


\section{Conclusion}

During the long-term operation under the influence of high temperatures there is a premature erosive wear of a heat-resistant covering that leads to the outburning of the surface layers of the basic material of a blade. Zones near the cooling channels are susceptible to degradation the most and that leads to the appearance of cracks. Degradation of material is reflected in microstructural changes that leads to decrease in mechanical characteristics of material. In other zones of a working surface and internal volumes of a blade the material keep the relevant microstructure. In order to avoid an outburning of the material in zones of the cooling channels and to protect the material against hightemperature and erosive influences of a gas stream, it is necessary to apply a heat-resistant covering on the blade airfoil.

Work was performed within the given state task by the Institute of Applied Physics of the Russian Academy of Sciences for carrying out fundamental scientific research during 2013-2020 on a subject No. 0035-2014-0401 (No. of state registration 01201458049).

\section{References}

1. A.V. Logunov, High-temperature nickel alloys for shovels and disks of gas turbines / Rybinsk: LLC Gazoturbinnye tekhnologii Publishing House, 854 pages (2017)

2. Y. P. Tarasenko, L. A. Krivina, I. N. Tsareva, O. B. Berdnik, A pulse mikronaplavka for repair technologies of turbine shovels from high-temperature nickel monocrystal alloys //Welding fabrication, v. 2, pp. 23-30 (2018)

3. D.A Kazanski, Development of criteria of operational reliability for workers and the directing shovels of the modern gas turbines // elst.energy-journals.ru.

4. Y.P. Tarasenko, S.V. Kirikov, O.B. Berdnik, L.A. Krivina, Resultant of a possibility of maintenance of material of shovels of turbines of power stations by methods of the quantitative analysis of the strengthening phases and researches of local mechanical characteristics//Questions of materials science, v. 2(90), pp. 49 - 57 (2017) 